\title{
Food as a Marker of Identity in My Beautiful Death by Eben Venter
}

\author{
By Alicia van der Spuy*
}

Food is often used in literature as a metaphor of culture, class and ethnicity. It is also used as the source of memories and tradition, as different foods can evoke memories of home, or be part of certain traditions, such as religious celebrations. Food can, however, also be used to break away from a traditional background, or it may be an act of rebellion. This paper investigates how food is used as a marker of identity in the novel "My Beautiful Death" by Eben Venter. The main character's relationship with and to food marks his changing identity, as well as his final farewell to life.

Keywords: Food, Identity, Interculturalism, Metaphor

\section{Background}

Eben Venter is a South African/Australian writer who grew up in South Africa on a sheep farm (Turnbull 2015), but immigrated to Australia in 1986 due to the declaration of a state of emergency ${ }^{1}$. Since 1986 he has published nine books, including a cook book. His novels have been translated into Dutch, German and English, and he has won numerous literary prizes. He was writerin-residence at the Netherlands Institute of Advanced Study, as well as Rhodes University in South Africa, and lectures by invitation at universities in the Netherlands, Japan and South Africa ${ }^{2}$.

My Beautiful Death (2006) is the English version of Venter's Afrikaans book, Ek stamel ek sterwe, which was first published in $1996^{3}$. The Dutch translation was issued in 1998 under the name Ik stamel ik sterf.

The novel relates the story of an Afrikaans speaking male named Konstant Wasserman, who grew up on a farm in South Africa. His biggest desire is to leave the farm and thus to escape the narrow-mindedness that he perceives in his family and the town's people.

Within a normative expectation of heterosexuality and the heritage of a farm culture (Crous 2012a), Konstant is expected to take over the family farm and produce the heirs who will, in turn, continue with the tradition. Afrikaans farm tradition dictates a culture of God-fearing Calvinism (Garisch 2015). This brings with it elements of shame, which are exacerbated due to the legacy of apartheid. However, Konstant cannot comply with his parents' wishes, as he is gay and would thus be unable to produce the necessary heir via conventional methods.

Konstant first moves to Johannesburg. This city serves as a transition between the known and the unknown, as he plans to move to Australia. In Johannesburg Konstant meets the enigmatic Jude, an openly gay person who transcends gender

\footnotetext{
* Senior Lecturer, Walter Sisulu University, South Africa.

${ }^{1}$ NB Publishers (n.d.) Author Focus Eben Venter. Retrieved from www.nb.co.za/Authors/1191.

${ }^{2}$ Ibid.

${ }^{3}$ Ibid.
} 
description based on his clothing and demeanour. To his joy, Konstant learns that Jude lives in Australia and decides to pursue him.

In Australia, Konstant experiences a freedom that he has never experienced before. He joins a vegetarian restaurant, first as a dishwasher and then as a cook. Here he meets with people from different cultural spheres and changes to a vegetarian diet. He is extremely proud of the way this new diet has changed his physique, because he looks good and feels good.

Both his gay lifestyle and his vegetarian diet represent a complete break from his traditional Afrikaans upbringing, and thus a break from South Africa and his identity as a South African. Vegetarianism is a subversive discourse (Crous 2012a) through which Konstant lives out his new life.

The irony is, as soon as Konstant feels that he has adapted to his new life in his new country, he is diagnosed with AIDS. This diagnosis challenges his view of himself, his background and his new life.

The name "Konstant" is loaded with meaning. On a literal level, it is a family name which is given to the first son in the family with the intention that he would in turn give this name to his firstborn son. It is derived from Latin, Konstantin, with the meaning of steadfast (Think Baby Names 2017). It is a name mostly given to boys, but it can also be used for girls. "Konstant" is currently not considered a popular name for boys in South Africa. It is ironic that Konstant is the one who wishes to change his life and emigrates, thus leaving everything that is familiar behind. He defies the meaning of his name in taking on an identity that is not "constant".

Similarities between the character Konstant Wasserman and Eben Venter, the author, are obvious. In fact, the character of Konstant Wasserman can be said to be loosely based on Venter's own experience of emigration and living in Australia.

\section{Methodology}

The researcher has used literature review and content (text) analysis as the methodology for this paper. The text, My Beautiful Death, by Eben Venter was analysed according to predetermined themes that relate to the topic of food. Content Analysis is a useful tool to systematically read a text according to a theme (Krippendorff 2013), in this case food. Elo and Kyngäs (2008) agree with this view.

A number of different methods may be used for an analysis of literature. Amongst these are New Criticism, Structuralism, Stylistics, the Reader Response approach, the Language Based approach and Critical Literacy (Van 2009). Critical Discourse Analysis would also be useful, especially when analysing a text for evidence of power relations or the "social elements of the discourse" (Van Dijk 1999). For this paper, a Critical Literature approach was used in order to explore the relationship between food and identity. 


\section{Food and Identity}

Food is a universal experience (Garisch 2015) that is part of all life. In the human experience, foodstuffs are loaded with social and moral meaning (McWilliams 2003), with connotations such as love and caring attached to the preparation of food, the serving of food and the eventual eating. What we eat can also call up memories of our pasts, and thus food can be considered a depository of our remembrance (Mercer and Strom 2007, Baena 2006). It can also serve to remind us of our traditions, as food is closely linked to cultural customs. The eating of certain foods can cause us to remember particular events, or specific people. Food is thus not only of physical importance, but it also has emotional significance (Brown et al. 2009).

Food is furthermore about social connections, because the shared preparation and communal consumption of food imply a bond between the people involved in these actions (Harrison 2001). The preparation of food can be seen as an activity that is fundamental to relationships (Brown et al. 2009), and especially to family bonds. It is in the familial space that the preparing and sharing of food mostly takes place, and it thus becomes a significant symbol of relationships within the family (Kitzinger and Kitzinger 1991). The mother who feeds her family is showing her love. If you have to feed yourself, you are using food as a substitute for love (Baxter and Hughes 2004).

The connection between food and home is very strong, and is normally positive (Brown et al. 2009), with associations of family unity, a mother's love and belonging to a culture connected to the consumption of home cooking. However, food can also be used to distance yourself from the home when a person refuses to eat the foods traditionally served to the family (Harrison 2001). This is an act of rebellion normally associated with children (Kitzinger and Kitzinger 1991) in the process of establishing their own identity, but can also be used as a weapon by adults. The rejection of food becomes symbolic of a struggle for selfsufficiency, because it may be the only means to protest and establish autonomy.

Because of this link between food and home, and food and culture, the food that we eat - or do not eat - is closely linked to our identity (Brown et al. 2009). Our food reflects our heritage (Kitzinger and Kitzinger 1991) and links us to our histories, whether personal or collective. Our eating habits cannot be divorced from our culture (Brown et al. 2009) and what you eat, as well as how you eat, provides comment on your social, religious and ethnic affiliation (Harrison 2001).

On the other hand, food can be used to question these affiliations. When one chooses to reject the foods of your family, you are essentially insulting your origins and excluding yourself from a shared custom (Harrison 2001). At the same time, in changing your diet, you give recognition to people who have different dietary habits and therefore different social and cultural traditions. Your selection of alternative foods indicates that you have control over your own body (Baxter and Hughes 2004), but it also suggests that you are aware of the fact that other people may make different choices and that you choose to align yourself with these people. Food consequently becomes an alternative to the dominant discourse (Williams 2007) and can be seen as a political choice (Mehta 2005). 
Within the Afrikaans culture - as in probably most cultures - the preparation and consumption of food takes a central place in family gatherings. Meat is an important part of the typical South African diet (Garisch 2015), and especially on the farms, as it is an item that is freely available. Often, however, the ingestion of meat is connected with wealth and luxury (McWilliams 2003, Crous 2012b). The fact that one is able to choose to eat meat marks them as part of the upper classes (Garisch 2015, Crous 2012b), and therefore part of the privileged and powerful. To choose not to eat meat - even when you are able to - is an enormous act of rebellion, because it provides an alternative to the dominant culture (Williams 2007). Vegetarianism offers a subversive alternative to the pervasive discourse of eating meat (Crous 2012b). In the face of a meat eating culture, becoming a vegetarian signals the absence of cultural and familial ties, whereas eating meat indicates the presence of these bonds (Mercer and Strom 2007). In the South African Afrikaans context, the refusal to eat meat is tantamount to rejecting your culture (Crous 2012b), and it will mark you as an outsider.

However, in contrast to the decadence associated with eating meat, the ultimate religious goal is to stop eating (Doniger 1999), because eating well is a worldly goal. Thus the act of denying meat ties in with the God-fearing, Cavinist, religious context (Garisch 2015) of the previously dominant Afrikaans culture. This is ironic given the importance that is given to meat and to eating well, and the idea that the absence of food takes away your culture and your memories (Baena 2006). The gesture of denying yourself food is associated with self-control, whereas eating too much shows that you are out of control physically and mentally (Baxter and Hughes 2004).

Food plays an important role in the lives of immigrants: by cooking traditional fare, they recall home and family. In fact, the immigrant's migrant identity is attached to the eating of traditional food (Baena 2006) - your choice of different foods, marks you as an outsider. This traditional cooking serves, as Brinda Mehta (2005) says, to "avoid amnesia".

Conversely, if immigrants wish to assimilate to the culture of the adopted country, they would also take on the food habits of the new country and thus culture. Food becomes a way in which to make the transition to this new world (Baena 2006) and the gateway to a transformation of the self. Not only do different foods consequently create an altered identity, but they serve to connect to the inhabitants of the new space.

It also needs to be noted that food is an object of pleasure (Crous 2012b) and that sensuous desires are provided by food and drink (Olivier 2013). The relationship between food and sex can be connected to the orality of food, as there is a correlation between pleasure and the mouth (Garza 2010). This relationship is often explored in movies and novels, such as Dis koue kos, Skat [It's Cold Food, Darling/Served Cold - my translation] (Van der Vyver 2010) and The Book of Love (Capella 2004).

Food is often seen as the preserve of women and "outside the symbolic order of masculinity" (Baxter and Hughes 2004, Baena 2006). A man who cooks especially at home - is perceived as an anomaly and outside the normative discourse of heterosexuality. A man who cooks is a man who has broken ties with 
his traditional background (Brown et al. 2009) and, in this case especially, his traditional Afrikaans background.

A discussion of food will not be complete without an examination of the bodily functions associated with the consumption of food. As human beings we tend to hide these acts as our food and society become more sophisticated (McWilliams 2003), yet they form part of the cycle of regeneration and degeneration (Crous 2012b) that is the mark of the human condition. Ingestion, digestion and excretion emphasise the "commonality of the human condition" (Harrison 2001) and serve to undermine any social differences.

It should be clear from this discussion that food is closely linked to identity, whether it is to reinforce this identity, or whether it provides an alternative to the dominant culture.

\section{My Beautiful Death}

Food is a central theme in the novel, My Beautiful Death (Venter 2006). The main character, Konstant Wasserman, details in a stream of consciousness his feelings, observations and the daily details of his life, including the food that he eats or prepares. He also observes other characters in terms of food and food smells. These opinions reflect his feelings towards that person and indicate his changing sentiments.

At the beginning of the novel, Konstant is sent to town by his father to buy ureum for the cattle (9). In town he gets angry at the lady serving him, and she comments that he "look[s] like [her] turkey" (15). When he moves to Johannesburg, he refers to himself as "tender meat" (34), a metaphor that indicates that he is in experienced and a farm boy. Just before he leaves Johannesburg he meets Martie, a school friend, who tries to seduce him. He thinks of her genitalia as "a steaming little pudding" (44), yet does not partake in the fare offered to him.

At a final, hedonistic party, Konstant meets Jude, a sexually ambivalent man who wears robes, dresses and jewellery. He falls hopelessly in love with a man whose unwillingness to commit is expressed from the first glance via his "raisin eyes" (48) that are impossible to judge. Konstant describes Jude's voice as honey (59), a quality that is especially prevalent when Jude has been cheating on him with another man. He also refers to Jude's easy technique to pick up other men as "honey" (62), inferring that he sets a trap with honey, an activity normally associated with women.

Jude lives according to his own values and operates outside the normative. He introduces Konstant to a hedonistic lifestyle, which consists of good food, good wine and good marijuana. Konstant easily adapts to these higher standards and more sophisticated ways of eating. Meat, the ultimate "taste of luxury" (McWilliams 2003), is initially part of this sophistication, but Konstant ultimately becomes sickened by the utter wastefulness of this existence just before he goes to Australia. The realisation that they are wasting food whilst others are unable to eat, appalls him (40). Nonetheless, this does not stop him from sending food back to the kitchen because it "does not match the description on the menu" (131), a habit he has picked up from Jude and that seems to him like the hight of sophistication. 
Konstant can be critical about the looks of the people he meet. On his flight to Australia he mentally talks about the cabin attendant's "Swiss roll" (75) when he wants to say that he is overweight. He thinks the passenger next to him, an elderly lady, has a face like a "saucer of intestines" (76), which is not a kind observation. $\mathrm{He}$ is especially critical about people he does not know, and greet people on the street as "Biscuitbum", "Ratface" and "Blackgall" (133). He also refers to his own beard as "prickly pear thorns" $(15,228)$. When Konstant has an altercation with a lawyer, he insults him by saying that he has a problem with his Adam's apple (140). This is of course far more significant than simply referring to a body part, as this insult implies a deep-seated issue with the man's obvious heterosexuality and macho superiority, signified by his suit, tie and briefcase.

$\mathrm{He}$ is more positive about people he likes or who he has a personal relationship with. On describing the people he has to work with in Australia, he pronounces that Shane smells like "sweet-potato syrup" (88), that Jamal is "as tender as a halaal lamb" (99) and that Liz reminds him of "a mushy pear with freckles" (111). He calls Liz a "sweetie pie" (128) and says that coffee makes him think of his brother (128). His final thought of food is related to the smell of his grandfather, who smelled like "white bread" (270).

After an incident when he encountered one of Jude's lovers, he becomes more critical of Jude and refers to Jude's "cabbage-soup farts" (65). He also thinks that Jude smells of "burnt olive oil" (90), a comparison that he repeats later (268), but in a more positive, resigned way, as he realises that he is close to death - the smell of Jude's body was "given to [him] to enjoy for a while".

Food is inextricably linked to culture and home (Brown et al. 2009) and would normally be a positive experience, with the food of home associated with love and caring (Kitzinger and Kitzinger 1991). However, Konstant's biggest desire is to leave home, because he associates the farm with small-mindedness and constrictions on his life. His father's expectations are for Konstant, his firstborn son, to take over the management of the farm, to get married and to, in his turn, have a son, who will become a farmer and, in effect, will oversee the family traditions and heritage. This is an unattainable dream, because Konstant is gay and will therefore not follow the traditional, normative, heterosexual path prescribed by the conservative farming community that is his home.

Konstant feels that he will lose himself if he stays at home. The move to Johannesburg and the eventual complete break with South African culture in the emigration from South Africa, are deemed necessary for him to become fully himself, in other words, to find his true identity. This is ironic because through the lifestyle that he adopts in his attempt to discover his own character, he contracts HIV, develops AIDS and eventually dies, thus truly losing himself.

In Johannesburg, Konstant starts to work at a restaurant (29). This is already contrary to the normative expectation that dictates that the culinary belongs to women (Baena 2006). This is therefore a subversive choice that goes against his culture and goes outside the symbolic order of masculinity (Baxter and Hughes 2004). He continues to work in a restaurant in Sydney, but this is an even more subversive option, as it is a vegetarian restaurant. This is contrary to the dominant 
Australian culture, which, like the South African culture, has meat as a primary food, with the "barbecue" playing a major role in society (Woodgate 2017).

At first he believes that vegetarian food will be boring (85), but Jude says that the food is "more sophisticated than lettuce and carrots". Konstant, who has ironically never been interested in a vegetable garden, discovers the meaning of organic vegetables, as well as the meaning of many different foods used in the restaurant, such as hijiki (92), tofu, bancha tea, agar-agar and kudzu (103). He is initially wary of the vegetarian food and does not think that he will ever eat it (96), but uses his knowledge of the Bible - Daniel and his friends only ate vegetables, were healthier than ever and did not burn in the fire (90) - to motivate for a vegetarian diet. This is, again, ironic, as his values have changed considerably since his move from the farm and religion is not important anymore. He also thinks that Shane is very calm and that this may be due to only eating vegetables (90). Joseph, another kitchen worker, says, in response to signs of Konstant's simmering temper, that he needs to eat less meat, because vegetables will keep him "mellow like soaked rice with the kernel of good sense intact" (95).

Konstant is slowly initiated into the world of the vegetarian and adopts the new diet along with his new lifestyle. This fresh way of life can be seen as a reaction to his culture and his upbringing, as both the vegetarian and homosexual lifestyles could be considered foreign to his background as a conservative farm boy. His rejection of his traditional foods signifies a rejection of the values and norms attached to these foods. It also indicates an adoption of a new identitity.

This new identity does not mean that he assimilates the values and traditions of his adopted country. In fact, his embracing of the vegetarian diet is contrary to the dominant cuisine of Australia. As an immigrant you can choose to assimilate or to disassociate from the prevailing discourse. One way to do this is through food choices. When Konstant chooses a vegetarian lifestyle, he chooses a transcultural way of life (Jansen 2003), because the vegetarian diet that he follows, is a fusion of Western and Eastern cuisine. He belongs neither to Australia nor to South Africa, but identifies as a hybridic, transcultural person who has redefined his own identity (Jansen 2003). Even the vegetarian restaurant where he works in Sydney is a transcultural space, with many of the workers immigrants from other counries.

Vegetarianism seems to suit Konstant, although he had initially felt that not eating meat makes him pale (120). He feels that he is looking good because of the new diet (130) and believes that he has more energy, because he does not eat meat (165). He is also aware of the fact that he gets many looks, due to his new and impressive physique.

Konstant does, however, transgress every now and then by going to a Greek restaurant and ordering lamb shank (130). He feels guilty about this, but his behaviour can be seen as an act of defiance against the strict dieticary rules that Jude imposes, and thus against Jude.

Konstant also expresses criticism towards the vegetarian diet, yet he does not do this openly. He believes that their customers are anaemic and "fragile" (142), because they do not eat meat. He also relates how a customer faints because she is not eating enough meat. 
The vegetarian diet makes Konstant very aware of his body. He is conscious of how his body reacts to a diet of vegetables only, and remarks that he is looking good, as well as feeling good (130). He is also proud of the fact that his bones are strong, because of his "rabbit food" (214), a derogatory term used in South Africa when describing green vegetables.

Meat is for Konstant intimately linked to home and traditions. On his way to Johannesburg he eats the food that his mother had packed him. This is quite ironic, as he leaves the farm to be independent and to get away from his family, yet he still eats the food that they had provided. When his father visits him in Johannesburg, he spends a lot of time selecting and cooking a lamb stew as a sign of his love (68) (Kitzinger and Kitzinger 1991). When his father rejects the stew, he also rejects Konstant's peace offering and his love.

On the plane to Sydney, Konstant says "farewell to all those tasty legs of lamb" (85) and wonders if he will ever see "boerewors" - a type of sausage - in his life (90). The sausage also has sexual connotations and may imply that he is not sure if he will ever again have sexual relations with an Afrikaans man. Not only is he saying goodbye to the literal food of his home country, but also to the figurative food of South Africa.

Konstant's emotional state is also connected to the food that he eats. When his father rejects his meal of lamb stew (68), he himelf ends up not eating the stew. Instead, he goes to a restaurant where they eat "delicate quails" (71) and drink champagne. Quails and champagne are luxurious delicacies and his consumption thereof indicates his rebellion against the values of his parents. Konstant does not eat when he is emotionally unwell. Jude constantly cheats on him. This affects his appetite, as well as his work (119). His go-to meal is rooibos tea with soya milk, because this is the "next best thing to mothers's milk" (116). Like a little boy, he needs his mother when he is in distress, but he specifically needs his mother's food.

Konstant focuses on preparing food when he is emotionally disturbed. He prepares the lamb stew for his father (69), but refuses to confront his father when he rejects this offer of love. Instead, he focuses on talking about the cut of the meat. After his AIDS diagnosis, he becomes an excellent chef and the customers compliment him on his new dishes (208). The preparing of food helps him to concentrate and not think about the grim diagnosis.

There are two dinners that constitute turning points in the novel and in Konstant's development. He tells his parents over dinner that he is leaving town to go to the big city. Before he relates the conversation with his parents, he describes the meal in great detail:

Lamb chops, browned on the stove and then left to simmer with a dash of water until tender and smooth like marrow. Braised meat with white rice, boiled potatoes for $\mathrm{Pa}$. And a cucumber salad with pepper and grape vinegar (18).

Mentally he is distancing himself from the event, but his mother notices that something is wrong - she does not finish her meal (19). His father speaks for the collective when he says that Konstant will leave without his blessing (20) and indicates with this act that he is the patriarch and that they live in a 
patriarchal society. What he does not realise is that Konstant is rebelling against this normative discourse.

The second meal is prepared by Jude. Ironically, this meals comes at a time when Konstant does not want to even talk about food (134). Jude has chosen a "delicious, grain-fed hen" for the supper. This surprises Konstant, as it is poultry. As soon as Konstant discovers that Jude has a serious relationship with somebody else, he loses his appetite (137), just like his mother did when he broke his news to the family.

Meals are supposed to bring people together, because shared food is a sing of solidarity (Harrison 2001). Here the meals are used to show the breakdown of relationships between people, first between Konstant and his family and then between Konstant and Jude. The serving of the meal marks the collapse of the relationship as it was up to that stage. Breaks in connections do not necessarily mean failure of the relationships - these interruptions may actually lead to the rebuilding of new relationships. This is the case with Konstant and his family, as well as Konstant and Jude. The relationships are different, but more mature, because Konstant has found his own identity through distancing himself from his family and, eventually, Jude.

After Konstant is diagnosed with AIDS, he starts to eat meat again. He is advised by a naturopath to eat "calf liver with red adzuku beas and black sesame seeds" (231), as this will cure his "splenetic liver". He imports his brother to Australia to come and cook his mother's dishes (243). Albert, his brother, will even bring the traditional cookbook, Cook and Enjoy. This is a cookbook that is quintessentially South African. It contains traditional recipes and all the traditional Afrikaans cooking methods. Their mother taught Albert to prepare her recipes (243). This is contrary to the normative Afrikaans expectation of a man cooking, yet the parents show their love by allowing this unconventional event. The outcome of this is that the food traditions are handed down not to the daughters, but to the sons.

Food in this sense is used as comforter. When Konstant turns to past foods, he also turns to the past by recreating the familiar (McWilliams 2003). Where at first he was denying his connotations to what he calls the "mother land" (77), Konstant is now returning to his beginnings. It must be noted that Afrikaans does not use the term "mother land" to describe the country of origin, but rather the designator "father land". This evokes food images, in that the mother is the provider of nourishment. However, not only does she prepare and provide food; she also gives life.

The eating of meat disturbs Jude considerably and he makes "scornful remarks" about the "meaty dishes" in their "vegetarian home" (255). Jude is resentful of the fact that Albert's attention to Konstant is more important to Konstant. He tries to regain his power over Konstant by demeaning his food and eating habits (Garza 2010), yet it is too late. Konstant realises that he is dying and in the light of that fact, everything that used to be important, becomes unimportant - even his relationship with Jude.

The consumption of his traditional foods returns Konstant to the values of his culture. He has tried on a new identity, but in the process has discovered his own 
identity. He makes his own choices about what he wants to eat and thus about what is good for him. He also discovers that his personality is very similar to his father. According to him they share the same "prickly pear thorns" beard (228), which he had described on himself at the beginning of the novel (15). This is a reference to their similar tempers. In acknowledging the fact of his similarity to his father, he also acknowledges their shared values. Konstant has come full circle when he realises this connection with his father. He finds his own identity at that moment.

Before he dies of AIDS, he eats the food of home in an attempt to connect with his past, but also in an effort to connect with a healthier state of being. The choice of meat becomes the subversive discourse within the culture that he has installed himself, namely a vegetarian interculture, instead of a transculture.

In the end Konstant dies not thinking of food, but of water. He has no desire for food (266) and only wants water. Water is essential to all life, but ironically it is his final meal. He thus achieves the ultimate religious goal, namely starvation (Doniger 1999). He inadvertently gives up eating well in exchange for a possible spiritual existence.

At this point, Konstant's stream of consciousness runs out. The final word he utters is "I" (271). This signifies that all he is left with, is himself and his own identity. He has finally transformed himself to the essence of himself by redifining his identity (Jansen 2003).

\section{Conclusion}

Konstant's food choices follow his development as a character. At home he eats the traditional foods served by his mother, but in Johannesburg he developes a taste for a more hedonistic lifestyle. This includes seafood, drugs and alcohol. In Australia, however, Konstant changes his diet to a vegetarian one. This is part of his effort to convince Jude to love him, but it changes his body and the way he thinks about himself. He is actually proud of the person he had become.

When Konstantly finally dies, he seems to see his Grandfather, "Oupa Konstant" (270). This sighting connects him to the past and to his identity as Konstant Wasserman. The last word of the novel, "I" (271), reflects the idea that only the soul is left - the ultimate identity.

\section{Recommendations}

My Beautiful Death is a rich novel with many layers that still need to be explored. Topics that were not touched on in this paper are issues of the food metaphor, death as a process, as well as the very literal translation of Afrikaans expressions. The power relations evoked by the use of language and, in this case, food and the language around food, was touched on, but not analysed in detail. All of these could and should be further investigated. 


\section{References}

Baena R (2006) Gastro-graphy: Food as Metaphor in Fred Wah's Diamond Grill and Austin Clarke's Pig Tails 'n Breadfruit. Canadian Ethnic Studies/Etudes ethniques au Canada 38(1): 105-115.

Baxter L, Hughes C (2004) Tongue Sandwich and Bagel Days: Sex, food and Mind-Body Dualism. Gender, Work and Organization 11(4): 363-380.

Brown L, Edwards J, Hartwell H (2009) A Taste of the Unfamiliar. Understanding the Meanings Attached to Food by International Postgraduate Students in England. Appetite 54: 202-207.

Capella A (2004) The Food of Love. New York: Viking.

Crous M (2012a) Eben Venter as gewete van die vleiseters. Journal of Literary Studies 28(1): 69-69.

Crous M (2012b) Introduction: Speciial Issue Der Mensch ist was er isst (Feuerbach) Texts on Food, the Eating Process and the Philosphy of Recpes. Journal of Literary Studies 28(1): 1-3.

Doniger W (1999) Eating Karma in Classical South Asian Texts. Social Research 66(1): 151-165.

Elo S, Kyngäs H (2008) The Qualitative content analysis process. Journal of Advanced Nursing 62(1): 107-115.

Garisch MI (2015) Consuming Pasts: Imagining Food as Identity and (Post)memory in Post-Apartheid South Africa. Rhodes University. Grahamstown: Rhodes University.

Garza MA (2010) Cooking up the Politics of Identity, Corporeality, and Culture: Humor and Subversion in Denise Chavez's Loving Pedro Infante. Confluencia 26(1): 7083.

Harrison HL (2001) Myths and Metaphhors of Food in Oyono's Une Vie de Boy. The French Review 74(5): 924-933.

Jansen E (2003) "Ampie aan die Amstel": De creatieve energie grensoverschrijding in de Zuid-Afrikaanse letterkunde ("Ampie to that Amstel": The creative energy border crossing in South African literature). Stilet 15(2): 84-110.

Kitzinger S, Kitzinger C (1991) Food as Metaphor. Mothering 91(61): 42-47.

Krippendorff K (2013) Content Analysis: An Introduction to its Methodology. Thousand Oaks: SAGE.

McWilliams M (2003) Food and the Novel in Early America. Early American Literature 38(3): 365-393.

Mehta B (2005) Culinary Diasporas: Identity and the Language of Food in Gisele Pineau's Un papillon dan la cite and L'Exil selon Julia (Culinary Diasporas: Identity and the Language of Food in Gisele Pineau's A Butterfly in the City and Exile according to Julia). International Journal of Francophone Studies 8(1): 23-51.

Mercer L, Strom L (2007) Counter Narratives: Cooking up Stories of Love and Loss in Naomi Shihab Nye's Poetry and Diana Abu-Jaber's Crescent. MELUS 32(4): 33-46.

Olivier B (2013) The Pleasures of Food, and the Spiritual: Eat, Pray, love and Babette's Feast. Journal of Literary Studies 28(1): 21-39.

Think Baby Names (2017) Retrieved from http://www.thinkbabynames.com/meaning/ $1 /$ Konstant.

Turnbull S (2015, July 24) Behind the Book: Eben Venter. Retrieved from goo.gl/gm TKGK. 
Vol. 5, No. $1 \quad$ van der Spuy: Food as a Marker of Identity in My Beautiful Death...

Van TTM (2009) The Relevance of Literary Analysis to Teaching Literature. English Teaching Forum 3: 2-17.

Van der Vyver M (2010) Dis koue kos, skat (It's cold food, honey). Cape Town: NB Books.

Van Dijk TA (1999) Editorial: Critical Discourse Analysis and Conversation Analysis. Discourse and Society 10(4): 459-460

Venter E (2006) My Beautiful Death. Cape Town: Tafelberg.

Williams LA (2007) Foodways and Subjectivity in Jhumpa Lahiri's Interpreter of Maladies. MELUS 32(4): 69-79.

Woodgate T (2017) Australian Food: 40 Dishes Locals Like to Call their Own. Retrieved from https://edition.cnn.com/travel/article/australian-food/index.html. 